\title{
Getting to the Root of the Matter
}

Cubans are known the world over for their inventiveness, doubtless borne of necessity, but also informed by higher educational levels than in many developing countries. In this issue, we present innovative approaches_-both practical and radical, both of proven benefit and still to be validated-from the front lines of Cuban population health and clinical research.

Fourteen years before the Lalonde Report, Cuba's emerging public health model contributed to what we would now call a multisector strategy to address the social and economic determinants of health. Its three prongs were a rural medical program, sending newly graduated MDs to address the needs of sorely underserved rural and remote communities; an ambitious campaign to eradicate illiteracy, a critical determinant of health and wellbeing; and land reform, to tackle the fundamental issue of rural poverty.

In this MEDICC Review, Rojas Ochoa, one of the first wave of rural doctors in the new program and now a veteran public health physician, provides testimony about his experience, personally and professionally (A Personal Reflection on Rural Service 50 Years Later). And Senior Editor Conner Gorry visits eastern Cuba to report on the evolution of rural health in Cuba over the last half century (Over the Hills \& Far Away: Rural Health in Cuba).

In Organization and Startup of The Gambia's New CommunityBased Medical Programme, Chávez shares lessons learned from the planning and early implementation phases of a program to train doctors in rural areas most in need of medical services in this small African country, one of the poorest on the continent. The program, launched through bilateral accords between Cuban and Gambian authorities, was created on the principle - supported by a number of recent studies - that physicians who come from and are trained in rural areas are more likely to remain there for their medical practice.

Author Chávez suggests that the outcome of the program bears careful monitoring, as a potential model for other nations whose populations suffer from scarcity of qualified health professionals and from the brain drain that is partially responsible.

Returning to Cuba, Peña's research on lipid levels in diabetics (Lipid Levels as Predictors of Silent Myocardial Ischemia in a Type 2 Diabetic Population in Havana) shows how routine laboratory tests can be used in a strategy to employ scarce diagnostic imaging resources most efficiently, by refining risk characterization vis-à-vis myocardial ischemia. In a similar vein, Galbán presents results of making endoscopy services more accessible to the population by placing them in primary care settings (Endoscopic Findings and Associated Risk Factors in Primary Health Care Settings in Havana, Cuba).

In some countries, declining public confidence in immunization and resulting loss of herd immunity have led to the resurgence of vaccine-preventable diseases. Surveillance of vaccinerelated adverse events supports immunization programs by helping decision makers and the public put adverse events in perspective. In this issue, Galindo describes two decades of national monitoring in Cuba (Vaccine-Related Adverse Events in Cuban Children, 1999-2008), a country with high rates of vaccination.

In other research, Pedroso reports on establishing proof of concept for a novel use of recombinant erythropoietin (Use of Cuban Recombinant Human Erythropoietin in Parkinson's Disease Treatment) and Díaz describes an approach to refining the differential diagnosis of HIV-1 and -2 (HIV-2 Antibody Detection after Indeterminate or Negative HIV-1 Western Blot in Cuba, 2005-2008)_innovative efforts to seek improved diagnosis and treatment.

Calixto Machado is internationally known for his work on definition of brain death (see MEDICC Review Oct 2010). In this issue, he discusses work by the Cuban Group for Study of Disorders of Consciousness questioning some currently held notions about persons in what has been termed "permanent vegetative states"- $a$ term he also rejects as pejorative. The evidence presented, albeit from a small number of cases, may challenge the idea that by definition they are isolated from the outside world (A Cuban Perspective on Management of Persistent Vegetative State).

Fourteen years before
the Lalonde Report,
Cuba's emerging public
health model contrib-
uted to what we would
now call a multisector
strategy...

This issue's focus on "frontline research" would not be complete without the reprint of Carlos J. Finlay's landmark -and at the time heretical-address in 1881, proposing the mosquito as the carrier of yellow fever (The Mosquito Hypothetically Considered as the Transmitting Agent of Yellow Fever). Finlay's paper is a model of meticulous observation and rigorous scientific method applied to a practical problem of immense importance for public health, setting a standard for a combination of rigor and practicality that remains of utmost relevance today.

We take this opportunity to thank all those who contributed to the journal by reviewing manuscripts in 2011 (Peer Reviewers). We are also pleased to share with you the good news that MEDICC Review is now indexed in the SciELO Public Health Collection, further enhancing its online availability. With this issue, we have changed to a controlled circulation model for the print edition, aimed at a selected readership. If you are interested in receiving the print edition, please write review@medicc.org; the online edition will continue to be freely available to readers as an Open Access publication. - 1/

\section{The Editors}

